\title{
Remix, literacy and creativity: An analytic review of the research literature
}

\author{
Michele Knobel $^{\text {a1 }}$ \\ ${ }^{a}$ Department of Early Childhood, Elementary \& Literacy Education, \\ Montclair State University
}

\begin{abstract}
Creativity is often identified as a key factor contributing to national economic growth and as an important life skill for personal and group wellbeing. Therefore, it is worth taking a close look at "creativity" as a concept and a practice, and to examine what might be at stake when grouping them together, especially in relation to schooling. The situation at schools is in marked contrast to a sizeable body of out-of-school research which shows how people are being creative and imaginative in their meaning making practices, especially within remix practices. The purpose of the paper is to survey existing English language research on digital remix and literacy with a view to identifying patterns across these studies that speak of the ways in which ordinary, everyday people have been practicing creativity. In the course of conducting this analytic review empirical publications published in English over the past two decades were examined and an overview of scientific literature on remix and literacy in out-of-school spaces was drawn up, identifying interesting patterns regarding creative endeavor and meaning making that might usefully inform classroom pedagogy. A related aim was to identify patterns concerning how digital remix and literacy have been studied to date. All of the 36 reviewed studies emphasise how approaching creativity as a thoroughly social phenomenon helps to confront instrumental approaches. The remix work documented in these studies show how committed people are to deliberately work at "being creative" and how that may help people to creatively engage with, or respond to, the rapid pace of change, with existing and emerging social, governmental and environmental problems, as well as to establish and maintain relationships across distance and differences.
\end{abstract}

Keywords: creativity, literacy, digital remix, pedagogical practice, fans, new literacies

Department of Early Childhood, Elementary \& Literacy Education, Montclair State University, 1 Normal Ave., University Hall 3163, 07043 Montclair, United States of America; knobelm@mail.montclair.edu 


\section{Introduction}

"Creativity" is on the social radar again, as theorists and pundits identify it as a key factor in national economic growth (e.g., Boccella \& Salerno, 2016; Florida, 2012), or as an important life skill for personal and group wellbeing and/or cultural expression (e.g., Stickley et al., 2017). "Creativity" is difficult to pin down, however, as its definition has undergone a range of changes since the 1950s. That being said, and given the current strong push to causally connect creativity to economic wellbeing, it is worth taking a close look at "creativity" as a concept and a practice, and to examine what might be at stake under such a coupling, especially in relation to schooling and, I argue, literacy learning.

Fostering creativity within the context of literacy learning has been a reasonably visible aim - or ideal-within education for the past 100 years or so (cf. Beghetto \& Kaufman, 2017; Hinsdale, 1900). And yet, current education policies and standardized literacy assessment practices within countries like the U.S., for example, seem to be leaving little room for students to creatively "muck around" with words, images, sounds, etc. as they generate and share ideas and meanings. Teacher-created literacy curriculum materials and goals are becoming scarce items in many schools in the U.S. and elsewhere, and have been replaced by commercial curriculum packages or by schoolwide mandates that lock curriculum into specific content or reductive understandings of literacy (cf. critiques in Knobel \& Kalman, 2016). Under these conditions, teachers and students are discouraged from taking risks with their literacy learning and the resources on which they draw. There certainly seems to be few opportunities for being creative or for promoting creativity under such conditions.

This situation stands in marked contrast to a sizeable body of out-of-school literacy research which shows how people are being creative and imaginative in their meaning making practices, and especially within remix practices. Remix can be described as taking existing cultural artefacts and recombining them into new kinds of creative blends and products (e.g., machinima, fan fiction, game modding). This remixing often requires the development or refinement of literacy practices that are valued in schools and, just as importantly, in other social spheres (e.g., work, leisure, social action). In fact, a close examination of digital remix and literacy research may bring to light interesting trends and patterns regarding what we can learn from studying young people's remix and literacies and perhaps speak to a robust and enriching conception of creativity, literacy and learning for classrooms.

The purpose of this paper is to survey existing English-language research on digital remix and literacy with a view to identifying patterns across these 
studies that speak of the ways in which ordinary, everyday people across the past two decades or so have been practicing creativity or "being creative". This purpose includes examining how digital remix and literacies have also been studied. In concert with this purpose, this paper has three aims. The first is theoretical in orientation and entails arguing for a social conception of creativity, with a particular focus on literacy, in order to inform how teachers might usefully think about creativity and literacy in their classrooms. The second aim is more practical in orientation and entails examining what existing digital remix and literacy research can tell us about people's literacy and creativity outside schools and what these creative practices might have to say in terms of inspiring pedagogical responses or take-up within classroom contexts. The third aim is to provide a "map" of sorts with respect to how digital remix, literacies and creativity have been studied to date, and what this tells us about this research focus in general and what it might point towards in terms of where more work might fruitfully be done.

\section{Creativity}

Creativity as a concept has an interesting history dominated by at least two discourses-both of them highly individualistic (Lankshear \& Knobel, 2015; Wilson, 2010). First, from the 1920s to roughly the 1970s, "creativity" was regarded as an individual mental property and was studied principally by psychologists who saw creativity as the province of individuals who worked alone within recognized fields of high status activity (like science and mathematics, or fine arts and writing). In short, creativity was regarded as a property of "elite" humans (Runco \& Albert, 2010). Second, and in rather stark contrast to the first orientation just described, creativity was seen by many as something more "holistic" in nature (albeit still highly individual). This orientation was grounded in the work of Montessori and Freud, and-especially from the 1950s onwards-viewed "creativity" from "naturalistic," "holistic" and developmental standpoints (Runco \& Albert, 2010). Some standpoints within this orientation emphasized creativity as integral to healthy "self-actualization," or "free expression." Focus was on the creative process over products. Ordinary, everyday kinds of creativity (in contrast to "excellent" or "groundbreaking" creativity as judged by experts) were viewed as a hallmark of healthy and effective living. Notwithstanding their differences, these two discourses of creativity shared a number of characteristics. In particular, in both cases creativity was to a large extent valued intrinsically rather than functionally or instrumentally. Both discourses tended to view creativity as residing deeply within the 
individual. And both tended to emphasize internal processes, inner states, and personal "ownership" of creativity.

Starting in the 1970s, however, four developments broadened the focus on creativity and moved it away from its original individualist, innate and, often, elitist orientation, as well as from its status as an intrinsic, self-actualizing good: 1. The increasing popularity of sociocultural theory among western academics and understanding language and literacy as a social phenomena;

2. Major developments in digital electronic technologies and their increasing pervasiveness in everyday life;

3. The emergence and maturing of a "new capitalism" and things like teambased approaches to production, worker "empowerment" and calls for workers to be "thinkers," innovative problem solvers and "ideas people" etc.; and

4. Policy and business emphasis on the importance of "responding to uncertainty and rapid change" as a major contemporary theme (for more on these trends see: Gee, Hull, \& Lankshear, 1996; Lankshear \& Knobel, 2015).

During the 1980s and 1990s, the move towards more social conceptions of cognition and activity - building principally on the work of Vygotsky (1978) challenged scholars' focus on individuals' interior states and processes and shifted attention to understanding things like language and thought as situated, contextualized processes and practices that drew directly on social interactions and "insider" understandings of social practices. At the same time, the rise of increasingly accessible digital networks and "online living" expanded conceptions of "the social" and generated growing opportunities for everyday people to share ideas, resources, insights, knowhow and the like with others both near and far. In business, competition and profits became geared towards providing customizable products-which in turn required production to be fast, flexible and responsive. Conceiving new products, envisaging and developing new materials, finding new ways of doing things, and so on, became all-important. Thus, in the 1990s and onwards, workers in developed countries were asked to be "innovators" and "problem solvers" and "ideas people" regardless of their place within the organization.

This emphasis on "rapid change," intense competition and the need for flexibility filtered into everyday life with a growing sense that everyone had to be innovative in order to prosper or even survive within a "fast capitalist" world (Gee et al., 1996). Knowledge, understood as the capacity to make use of information to act effectively, came to be seen as the key to successfully managing change, uncertainty and sustainability. This, in turn, saw the rise of concepts and claims to do with the importance of the "knowledge economy" and the wider "knowledge society," where knowledge is widely shared among interested 
parties. A key point here is that knowledge generation and sharing was no longer the sole province of professional or certified experts; what mattered now was a passionate interest and keenness to contribute (and not necessarily for monetary gain, either) (Lankshear \& Knobel, 2015).

These four developments helped usher in distinctively new discourses regarding creativity from the 1990s onwards. Creativity now was valued in terms of generating economic growth and profit (cf. Florida, 2012). This emphasis on creativity's instrumentalism and functionality casts creativity as a social imperative because it is now a basic economic survival skill. In addition, creativity now is recognized as having multiple forms and purposes. Scholars like Kaufman and Beghetto (2009) differentiate these forms along a continuum of process and production. For them, "mini c" creativity describes transformative learning in which everyday people make personally meaningful interpretations of actions, insights and experiences; "little c" creativity describes routine everyday problem solving, workarounds, and creative expressions (often within work contexts); "Pro-C" creativity describes professional or vocational creativity that is significant but not eminent; and "Big C" creativity is recognized as major or "great" within a field. These distinctions enable us to talk about all kinds of creativity within all kinds of social and economic spheres by releasing the concept from the twofold "genius" and "free expression" definitions of creativity that dominated the 1970s.

In addition, creativity now is seen as something that can be distributed. That is, it can be deeply networked and interconnected and involve large numbers of people. Massively distributed fan remixes, such as the extraordinary Star Wars Uncut remake that saw hundreds of fans each remaking 15 seconds of the original Star Wars movie (using Lego, live action or animation etc.) and then splicing them together to recreate the movie, are an excellent example of distributed creativity (see StarWarsUncut.com). This contrasts markedly with the promotion of the single, solitary genius or artist at the heart of creativity in the 1970s and earlier. This shift also draws attention to the conditions under which creativity is fostered. Florida (2012), a noted proponent of the "creative class," argues that conditions conducive to creativity include the diversity of ideas and people, possibilities for collective creativity, and social spaces that are both open and inclusive, among others. Thus, creativity can be, and often is, deeply social. This is more than simply working collaboratively on a creative project; it refers to a sense of "belonging" often spoken about by people involved in a shared creative act and how creativity is often seen as part of participating in something larger (whether it be contributing to an infectious meme or contagious idea online, taking part in a shared joke, writing clever placards to use in a demonstration march, etc.) (Knobel \& Lankshear, 2007). 
In summary, contemporary creativity discourses privilege distributed collaborative activity, instrumental value and purpose, diverse forms of creativity, and a radical democratizing of who can reasonably be perceived as purposefully manifesting creativity. Creative accomplishment is social before it is private, and largely externalized rather than "interior" and "private." Importantly, creativity does not occur in a vacuum. It always arises within some context and involves drawing on resources, purposes, challenges, and the like that already exist, and then doing something that transcends what already exists. The problem here, however, is that an emphasis on instrumental creativity-creativity that generates profits-regularly dominates current talk about creativity (Boccella \& Salerno, 2016; Wilson, 2010). This is troubling because-just as with elitist conceptions of creativity that characterized the 1950s to 1970s-everyday kinds of creativity that people report finding deeply satisfying or that make them feel part of something larger can be sidelined or ignored. Examining sociocultural conceptions of literacy and new literacies, such as digital remix, in particular, affords useful insights into this kind of everyday, multifaceted and highly participatory creativity and provides important leverage points for thinking more carefully about how this kind of creativity might be acknowledged and encouraged in school classrooms.

\section{Literacy and new literacies}

The push for schools to prepare students for creative industry work has been strong across Europe and countries like Australia for some time now (e.g., Beghetto \& Kaufman, 2017; Cloonan, Hutchison, \& Paatsch, 2015; Craft, 2003). This holds particular implications for literacy teachers-given how easy it is to argue that literacy is an important vehicle for creativity-and how literacy is defined and practiced in schools. Understanding literacy as a thoroughly social practice, and recognizing that there is no single way of "being literate" opens up an important door for understanding just how dynamic the relationship between literacies_especially new literacies_and creativity can be.

\section{Literacy is a social practice}

Literacy is best understood as a social practice. That is, it is concerned with being able to make, share, negotiate, coordinate and interpret meanings by drawing on sets of tools, skills and knowledge in socially recognized ways (Lankshear \& Knobel, 2011). Literacy, in this sense, is always multiple; that is, there is no single, fixed-in-time-and-space way of using meaning-making resources, but, rather, multiple ways of making sense that change according to 
the practice in which they are being used and the purpose to which they are being put (Gee, 2012; Lankshear \& Knobel, 2011; Street, 1984). What's most important for my purposes here is the socially recognized ways dimension of literacy which captures how literacies are not static, but change according to purpose, context, who's involved, and what happens when new tools, skills and knowledge come along that subtly-or not so subtly-shift and change the practice and, hence, what counts as "literacy" within that practice or larger social domain. A key point here is that social practices and their literacies are generative-oftentimes people will spot a need and develop a tool or resource in response which, in turn, generates new ways of thinking and speaking about things (e.g., the development of Real Simple Syndication for subscribing to blogs, generating in turn new online aggregation services and new ways of speaking about blogs and blog subscribers). We see this particularly in relation to "new" literacies.

\section{New literacies}

"New literacies," in a nutshell, is a useful concept for talking about literacy practices that have arisen in relationship with new technologies and affordances for meaning making and the social practices-many of which are also new-that make use of these tools, processes, and resources. New literacies do not presuppose use of digital technologies and media (e.g., video remixing predates digital times), although my focus here is on those that do. To begin, it is useful to think about new literacies in terms of new technical stuff and new ethos stuff. In terms of technical stuff, new literacies differ fundamentally from conventional print literacies in that their inscriptions are rendered-at least initially-by means of digital code rather than by material means (whether printed and illustrated/imaged/diagrammed by hand, typewriter or press). This means it is possible to access all kinds of services, repositories and networks distributed across time and space, participate in a range of practices by accessing people and services on a scale never before possible, and contribute ideas, digital artefacts and resources to a shared interest or endeavour by tapping an icon or key, and so on (Lankshear \& Knobel, 2011).

The "ethos" stuff of new literacies attends to the ways in which these new literacies are more participatory, collaborative, and distributed, and less "published," less "author-centric" and less "individual" than conventional literacies. Typically, engaging in social media sites, affinity spaces (Gee, 2013), and within environments and practices of participatory cultures (Jenkins, Ito, \& boyd, 2015), involves deep interactivity, openness to feedback, sharing resources and expertise, and a will to collaborate and provide support that is writ large in 
myriad contemporary everyday practices. Participants in new literacy practices often actively seek out memberships and peers in areas of affinity and interest and pursue different kinds of relationships between "authors" and "audiences" from those characterizing many conventional literacy practices. They generally value attending to the interests and knowledge of others, recognize that quality is judged by groups rather than by appointed experts, they welcome diversity of opinion in decision-making, and so on. This broad "ethos" of new literacies sets them apart from simply being conventional literacies in digital form (Lankshear \& Knobel, 2011).

\section{New literacies, appreciative systems and creativity}

An important dimension of any new literacy is what Gee (2007) calls an "appreciative system." When we are creating or producing something within a field of activity, aiming to get it as good as we can, as right as possible, and to perhaps create something that is significantly new in the process, we make "moves" in our work in light of what we know and what we have available, and then make qualitative judgments about what we have done. We make these judgments on the basis of appreciative systems that are relevant and appropriate to the activity we are in. Gee (2007, p. 172) describes them as value systems that are "embedded in the identities, tools, technologies, and world views of distinctive groups of people ... who share, sustain, and transform them." Thus, students soon come to understand that sending an e-mail to a teacher asking for an assignment extension but including all sorts of textspeak (e.g., "How R U?"), slang ("Wat up, fam!"), and spelling and grammatical errors is not going to help their case because they have not demonstrated due respect for the appreciative system that defines and shapes the kind of request they are making.

Interestingly, creativity is well recognised as occurring most fruitfully within sets of constraints or conventions (Florida, 2012). The act of doing something "creative" necessarily entails working within a particular context and drawing on resources, purposes, challenges, states of knowledge and accomplishment etc. that already exist in order to then do something that somehow transcends, re-orients or re-frames what already exists. Attention to appreciative systems helps us to identify materials, along with the rules, devices and codes that are the properties and resources of the domain or field of activity the creators are working within, and drawing upon, in order to innovate or "be creative."

These points have an important implication as to how we think about literacy in relation to creativity: namely, to be creative within a field of endeavour one must be proficient with the literacies and appreciative systems pertaining to the field. While there are any number of new literacies that can 
be examined in terms of "being creative," the social practice of digital remixing is especially apt.

\section{Digital remix}

Remix is a particularly ubiquitous practice that has it roots in non digital times, but which has been taken up widely since digital production tools and sharing networks have become more affordable and accessible (Lessig, 2009; Navas, Gallagher, \& burrough, 2015). As explained earlier, remix is the practice of taking existing cultural artefacts and recombining them into new kinds of creative blends and products. For example, remixing footage from Star Wars and Harry Potter movies can show an alternative story universe where Harry is evil. Digital remix recognizes that everyday people now have access to rich, multimedia resources and can be the creators or producers of their own images, music, or videos and the like, even if they are unable to take good photos, play an instrument, access actors and sets, and so on. So, while there are countless professional remixes to be found in the worlds of art, music, advertising, architecture, and the like, my particular interest in this paper is on amateur digital remixing and the insights it affords into literacy and everyday creativity. Popular digital remix practices include music remixing, political commentary media remixing, movie trailer remixing, fan movie remixing, machinima, anime music videos, photoshopping, fan art, fan fiction, game modding, and digital application mashups, to name just a few (see Lankshear \& Knobel, 2011 for more).

In many ways, do-it-yourself, amateur digital remix practices foster everyday creative capacity (i.e., more "little-c" creativity than "Pro-C" creativity) and make space for personally and collectively meaningful expressions of ideas and imagination that are all too often sidelined in schools where high-stakes testing and formal teacher accountability measures are the order of the day. Focussing on everyday creativity as a social practice rather than on professional or genius-level creativity may even provide important material for critiquing or tempering "creativity" as just another reified commodity. Focusing on everyday creativity, new literacies and digital remix, I also argue, can help inform classroom take-up of digital technologies and new literacies, reminding us as educators that simply using digital technologies to teach does not mean that we are engaging students in learning new literacies or in truly creative practices, and may instead simply be falling prey to the "old wine in new bottles" syndrome that has characterized a lot of digital technology take-up and claims regarding "creativity" in school for far too long. 


\section{Methods}

As a reminder, the purpose of this paper was to closely survey English language, empirical publications in order to conduct an analytic review of research published on remix and literacy in out-of-school spaces with the aim of identifying interesting patterns regarding creative endeavor and meaning making that might usefully inform classroom pedagogy. A related aim was to identify patterns concerning how digital remix and literacies have been studied to date, and what this might tell us about this particular investigative focus. Reviews of this kind typically are confined to journal articles, but my initial searches indicated a need to include research-based books and book chapters as well, due to the relatively small number of published studies I was finding.

Publications were identified using a range of search terms and academic search engines. Search terms included combinations of remix ${ }^{*}$, literac ${ }^{*}$, and creativ $^{\star}$ (where the asterisk enables searching for creativity, creative, etc.), along with terms such as bricolage, hybrid and mashup. This was supplemented with specific remix types, like machinima, photoshop, vids, shreds, etc. Literacy associated terms included: writing, composition, editing, narrative, and author*. Search engines were education-focused and included EBSCO, JStor, Proquest and Google Scholar. Exclusion criteria included papers that weren't studies, studies taking place in school or program-based settings, and studies that claimed to be about remix but weren't in any recognizable sense. This generated a set of 36 studies that substantially addressed aspects of literacy and creativity in digital remix (see Appendix 1). Due to the difficulty of deciding whether or not to include studies I considered to be focused on "remix" but where the researchers themselves did not necessarily use this term, this final set of articles is not exhaustive, but it does provide a good spread of research approaches and findings. It also must be said that (surprisingly) none of the studies surveyed included "creativity" as their focus, so my analysis of creative acts, processes and creativity as embodied in the report of each study is my extrapolation, based on what constitutes creative activity and production.

Studies were analyzed using a mix of open, process, and conceptual coding methods in a first cycle of analysis (cf. Saldaña, 2016). Open coding is a process whereby the researcher reads multiple times through the data-in this case, the 36 articles-and begins assigning codes based on salience to the purpose of the study (e.g., codes associated with research design, study participants, type of remix). These codes are refined during each subsequent reading. Process coding entails identifying actions within data (Saldaña, 2016) - in this case, action as reported in each study. Process codes comprise gerunds (i.e., "-ing" words) and were useful in the present analysis for foregrounding elements of 
remix and literacy activity (e.g., editing, modding, commenting, synching). My explicit interest in new literacies and creativity called for conceptual coding as well, where concepts and idea from the framing theoretical terrain were also used to identify salient elements within these 36 studies (all the while remaining careful to not over-interpret what I was seeing in the text of these studies. For example, I needed to recheck my codes regularly to make sure, for example, that instances of cooperation were not coded as collaboration given my particular interested in the latter). Conceptual codes included, for example, the four "Cs" of creativity outlined earlier in this paper, along with terms like collaboration, participation, distributed expertise, and so on. A second cycle of analysis reviewed these codes and grouped them into larger patterns that were usefully explanatory (cf. Saldaña, 2016). In what follows, I focus on patterns to do with the research studies themselves, followed by a discussion of patterns pertaining to digital remix, literacies and creativity.

\section{Outcomes and discussion}

\section{General patterns}

To begin, a number of large-scale patterns emerged from the analysis that proved interesting from a research standpoint. There was, for example, a noticeable upswing in the number of out-of-school, literacy-related studies that had remix in the publication title from 2013 onwards. This suggests remix and literacy are gaining ground with respect to research attention. The range of remix types addressed in these studies was interesting, too (for citations, see Appendix 1). The bulk of these studies focused on fan fiction-where fans take existing stories and remix them to create new narratives (e.g., Black, 2008; Curwood, 2013a; Eleá, 2012; Thomas, 2006); space precludes an exhaustive listing, but other remix types included:

- Music and music video remixes (e.g., Domingo, 2014a; Gustavson, 2008; Skågeby, 2011; Stedman, 2012; Strong \& Ossei-Owusu, 2014)

- Game modding communities and practices (e.g., Durga, 2012; Hayes \& Lee, 2012)

- Remixed videos (e.g., Keegan, 2010; Diakopoulos, Luther, Medynskiy, \& Essa, 2007)

- Language remix (e.g., Domingo, 2014a)

- Remix practices within fan-based communities or affinity spaces (e.g., Curwood, 2013b; Turk \& Johnson, 2012)

- Memes (Knobel \& Lankshear, 2007) 
Disciplines drawn on in the studies include sociology, anthropology, sociolinguistics, and cultural studies. Specific fields include composition and rhetoric studies, English and foreign language learning studies, literacy studies, media literacy studies, communication and journalism studies, and literacy and gaming, among others. Research designs ranged from multi-year ethnographies to single case studies to studies of websites and their archived resources and texts. Collectively, I argue, this range of remix types, theoretical orientations and study designs contributes to an understanding of remix and literacy (and creativity) that is usefully nuanced and multidimensional.

\section{Creativity, literacy and remix patterns}

A number of patterns spoke directly to the kinds of creativity and literacies being practiced by the ordinary, everyday people studied in the surveyed papers. These patterns include creativity as collaborative and participatory; how creative meaning making often draws on multiple expressive modes; that the original source materials do indeed remain important in remix and in setting creative boundaries; that meaning is often distributed across original source material and the new work created by a remixer; that remix creativity is often deeply social; and that creativity is often tied closely to personal passions and interests. Each of these patterns is discussed below.

Remix, as described in the studies surveyed for this paper, is clearly a creative act. Two Nigerian brothers remix hip hop and video to comment on African and American popular culture (Strong \& Ossei-Owusu, 2014). Fans remix video game music to create new tracks (Stedman, 2012). Gamers mod and remix game engines and content to create new levels within a game or new games altogether (Durga, 2012). Online photoshopping competitions generate clever and humorous images (Keegan, 2010). Found news reporting and other video footage is remixed into biting social commentary (Frølunde, 2012). Young people mix multiple languages online to signal identity and group membership (Domingo, 2014a, 2014b). And so on. The remix practices reported in this set of studies clearly resonate with key elements of current conceptions of "creativity" outlined earlier and that focus on creativity as a collaborative and participatory act, as a process of making meaning that is shared with others, and as a process that builds on what's come before and that adds a new or innovative twist. For example, fan fiction remixes in these studies are freely and openly shared with others-generally through some kind of portal (e.g., Fanfiction.net) or via a user-driven service (e.g., YouTube). Comments from readers, viewers and listeners underscore the importance of attending to producing engaging storylines, of not making characters act "out of character," of attending to grammar and spelling or video resolution quality, 
and of understanding the appreciative system that usefully constrains and enhances what is done with the original source material, and the like (many of which comprise valued literacy knowhow in schools). As one reviewer wrote in Black's study of fanfic author, Tanaka Nanako, "Let me point out that Li and Leing are from hong Kong, not China. since they're from hong Kong they should be speaking Cantonese but nevertheless i love it!" [sic] (2006, p. 178). This reviewer appreciated Nanako's creative use of multiple languages in her Card Captor Sakura anime remix narrative, but also wanted to help ensure character credibility in Nanako's story.

These studies collectively suggest that amateur remix practices are not at all invested in instrumental creativity that operates in the service of economic gain as a primary inducement to action. For example, Hayes and Yee (2012) document discussion on a game modding forum that shows how willing participants are to share their know- how regarding 3D modelling software for creating objects for The Sims (a popular online multiplayer game). This includes sharing hyperlinks to tutorials and files, advice on Google searches, software troubleshooting help, file type explanations, and the like. Other studies show how open remixers are to others taking their work and remixing that, too (e.g., Black, 2008). What is apparent across all of the 36 studies is an openness and generosity of spirit that is much more interested in relationships and shared enjoyment or appreciation of something, than in making money or "owning" something outright.

Not unexpectedly, fan-focused studies identified the value placed on remaining "true" to the original source material, while building on it in believable and appreciated ways. For example, Tanaka Nanako-mentioned above (e.g., Black, 2009a) —explores relationships that are underdeveloped in the original source material and which she and other fans find to be deeply satisfying extensions of the original anime. Unexpectedly, this attention to the appreciative system of a given remix practice also seems to include knowing when it's all right to do something "badly," such as including clichés or tired conventions in a photoshopped image for humorous results (e.g., Keegan, 2010).

The reviewed studies also show how the original source material matters very much - more than I had assumed originally—and that meaning and, thus, creativity are often distributed across knowledge of the original source material and interpretations of the new remixed work. That is, each element used from the source material brings with it its own universe of meaning. For example, Turk and Johnson (2012) write about a fan of the very popular Hawaii Five-O television series (itself a remake of the original series broadcast in the 1970s), who remixed video clips from across multiple episodes to suggest that the two principal and very heterosexual male characters were actually in love with each 
other (see: http://bit.ly/1lcPmVd). This was a popular relationship developed by fans and mirrors similar romantic pairings in other fandoms (e.g., Spock/ Kirk from Star Trek). The carefully selected and remixed clips-showing the characters bickering, gazing and/or smiling at each other, being repeatedly alone together, etc. - were set to the upbeat and romantic "Something's Gotta Give" sung by Frank Sinatra. The song's lyrics emphasize the inevitability of a love-based relationship even though this is not at all a part of the television show itself. The soundtrack by Sinatra is a deliberate nod on the remixer's part to the New Jersey (USA) origins of both Sinatra and Danny's character (Turk \& Johnson, 2012). The remixer also leverages the themes and scenarios of the episodes clips are drawn from to add yet further layers of meaning to her video. Comments appended to the video suggest that other fans found it highly enjoyable, satisfying, and well put together (Turk \& Johnson, 2012). Indeed, fans quickly identified various layers of meaning within the video based on their familiarity with the original episode from which each clip was taken (e.g., the clip of Danny waving Steve away dismissively was from an episode dealing with friendship and jealousy). This example also enables us to see how other fans acknowledge how this remixer paid attention to this fandom's appreciative system, too (e.g., she portrayed a popular romantic pairing, she leveraged meaning by selecting clips from thematically relevant episodes, she synched the music and video action carefully and tellingly). Thus, it's possible to read/ view/hear the remix productions documented in these studies as stand alone artefacts, but enjoyment and meaning is surely enhanced by being familiar with the original source material. As such, these remix studies suggest people are adept at creatively making meaning on multiple levels and for multiple readers/ viewers/listeners. This alone has significant implications for how educators design literacy instruction and meaning making opportunities in classrooms.

As mentioned earlier, Gee (2013) has identified what he calls online "affinity spaces" that, in brief, resource and support a shared interest or endeavor. Participation in these spaces is not segregated by age, race, class, or ability. Newcomers and experts alike share this space, and there are opportunities for both to produce and consume readily available resources. Specialist knowledge is pooled and shared and, while self-propelled learning is valued, calls for help are welcome. Affinity spaces seem to provide the right kind of generative and creative contexts for a range of remix practices and participation, and help to resource people's projects both in terms of content, access to insider expertise and evaluations, and technical help. The studies reviewed in this paper show how dedicated spaces like Fanfiction.net, Mockingjay.net, Lostvideo.net, AnimeMusicVideos.org, ccMixter, Overclocked Remix, along with more general user-content driven services like YouTube, Wattpad, Sound- 
click, Tumblr, seem to help people find others who share similar interests and fandoms, which in turn facilitates learning, and resource and idea sharing, as well as remix distribution across digital networks. This dimension of the studies underscores the deep socialness of creativity as practiced by many everyday people and emphasizes the important role networks play in distributing and archiving remixes, as well as how they facilitate access, affiliation and enjoyment.

Indeed, what many of these studies emphasize is that being creative in amateur digital remixing is very much tied to a person's passions and interests. There is little, if any, monetary return reported, but many people spend countless hours on their remixes, honing their "technical" knowhow and expertise as well as polishing and repolishing the ways in which they construct and convey meanings in their remix. For some remixers in the reviewed studies, reward takes the form of recognition and status within the remix community (Black, 2008; Curwood, 2013b; Curwood, Magnifico, \& Lammers, 2013; Domingo, 2014a; Strong \& Ossei-Owusu, 2014; Thomas, 2007a). In many ways, Jenkins and colleagues' (2015) concept of participatory culture checks in here, where remix practices are marked by low barriers to joining a creative endeavor and where so much of these endeavors is really about extending the enjoyment to be had from the original source material by reworking or adding to it. Indeed, it seems that the rewards for producing or consuming remixes come in the form of simply participating in the practice itself in many cases (see, for example, meme production in Knobel \& Lankshear, 2007; music remixing in Gustavson, 2008; Lost fan video production in Stedman, 2012).

Additional patterns worth closer scrutiny but with no space to address here include: identity work; social critique; humor and spoofing; hybrid genres; and collaborative authorship, to name a few. What is clear from the patterns identified across the 36 studies reviewed is that creative remix does not occur in a vacuum, but builds on the work of others (professionals and amateurs alike) and depends heavily on actively sharing this creative work with others, obtaining or providing feedback or commentary on remixes, and attending to the conventions and appreciative systems of the practice within which the remix is being produced. These studies re-emphasize how creativity-even small-scale, everyday creativity of the kind that is perhaps more personally satisfying than paradigm shifting-requires fruitful conditions to foster it. They also show us how remixers are able to talk very precisely about their creative decisions, and how these decisions draw on insider knowledge and fandoms, as well as on resource availability and technical knowhow. And, they re-emphasize the importance of understanding creativity as a social rather than an individual phenomenon. 


\section{Possible pedagogical responses to these outcomes}

Digital remix, quite clearly is not simply a matter of blending two or more resources to create something "new." In classroom settings, it is much, much more than simply transposing Shakespeare's Romeo and Juliet into modern times, or making a stop motion animation of an Edgar Allen Poe story. What this review strongly suggests is that creativity, literacy and digital remix are intimately connected and that any classroom take-up of remix practices must necessarily ensure that instruction and assessment needs do not inadvertently do away with enjoyment, opportunities for making meaning on multiple levels, attending to the appreciative systems of the original sources and fandoms involved, working collaboratively or in cycles of production, feedback and refinement, and so on. My intention here is not to pronounce on how digital remix and literacies should be "done" in classrooms; rather, the outcomes of this analytic review point to a range of guidelines that can usefully inform pedagogy. These guidelines include ensuring that students have the opportunity to create meaning using a range of modes (e.g., writing with the alphabet, with video footage, with music, with popular culture motifs and resources). This is much more than simply making space for creating multimedia texts; it is to recognize that within remix, various modes-alphabetic text, music, languages, game maps, image and music synching, video clip transitions, and so on-each carry meaning which contributes to the overall "sense" of a final remix. For example, the Hawaii Five-O video described earlier would mean something quite different if the soundtrack was changed to a song about rivalry. It also seems imperative for teachers to be "up with the play" with respect to the resources on which students are drawing when they do create remixes in order to really appreciate the creative meaning making that is taking place within students' productions. For example, being familiar with the Harry Potter as and The Hunger Games books and movies helps teachers to see more clearly innovative additions to existing storylines or character development arcs in a fan fiction text that remixes both of these universes. At the same time, teachers may need to rethink their own position on "original work" with respect to bringing remix into the classroom and recognize that a good deal of creative work in the commercial sphere often draws on previous works (cf., Disney's animated remixes of fairytales).

The outcomes of this review also seem to suggest it is important to provide students with plenty of time and space in which to really examine the affinity spaces that shape, support and resource a particular remix practice. The same appears to hold in terms of giving students time and space to tinker with ideas and remix possibilities, as well as time in which to rework and refine their 
remixes in light of feedback and their own attention to what's valued (both in a technical and an ethos sense) within this particular remix. In this way, students are likely to understand different appreciative systems and what is valued and what is not within a given practice (e.g., the checkerboard transition effect between video clips in Windows Live is considered cheesy and clumsy in anime music video remixing; be wary of taking popular characters and making them act outside their usual values and personality characteristics). They may also practice spotting clichéd storylines and remix motifs that can usefully feed into producing innovative rather than hackneyed work.

Enabling students to work with others inside and outside the classroom opens up all sorts of possibilities for accessing new ideas and insights into a particular practice-both in terms of refining expertise with the "technical stuff" of a given remix (e.g., splicing video, synching sound and movement, written grammar) and in terms of learning to work in collaborative ways that truly engage with generous dispositions towards sharing resources and expertise. This is not to argue for remix practices to be imported lock, stock and barrel into classrooms, either. Rather, it may well be the principles of digital remix and creativity that find useful leverage for learning (for more on this, see Knobel \& Lankshear, 2014). For example, in my own teaching, I approach academic writing as a remix practice and take seriously fan fiction writing practices that value constructive feedback from multiple people. To this end, my students write their assignment papers within Google Docs that are shared with groups of peers or the entire class and everyone reads and responds to work in progress in ways that typically lead to more refined and polished final texts.

Hearteningly, my literature search also showed that even within a regime of over-testing and teacher surveillance, there is nonetheless a growing body of classroom based studies that take remix practices and new literacies seriously and that provide hopeful and helpful guides for what can be done (e.g., Burn, 2009; Curwood \& Gibbons, 2010; Peppler, 2014). This is a development worth keeping in sight from both research and pedagogy angles.

\section{Conclusion}

These 36 reviewed studies underscore how approaching creativity as a thoroughly social phenomenon helps to confront instrumental approaches that emphasize "creative products" and which threaten to swamp other kinds of recognized and valued creativity (Wilson, 2010). These studies help us to see that creativity can be-and often is-part of human vitality without it devolving into a "we are all creative" relativism (Wilson, 2010, p. 7) that erases "creativity" as a meaningful concept. The remix work documented in these studies show 
how committed people are to reworking and refining their productions; and how they deliberately work at "being creative." The way in which digital remix practices celebrate fresh "spins" on the original source material and new ways of looking at what's already in place may even help people to creatively engage with or respond to the rapid pace of change, with existing and emerging social, governmental and environmental problems, to establish and maintain relationships across distance and differences, and so on (cf. discussions in Burwell, 2013; Wilson, 2010).

For me, reflecting on the outcomes of this review points to the need for teachers themselves to be creative. In my own work in preparing preservice teachers, I regularly encounter teacher education students who simply want to be told what they need to know and be able to do, and their default mode seems to be one of replicating tired and tedious approaches to literacy instruction (e.g., teaching five-part essays, weekly spelling lists to memorize). Perhaps having teacher education students closely examine and unpack the layers of meaning, collaboration, and creative work within digital remixes may help to remind them that creativity is the province of everyday people and that they, too, can be creative in their teaching-and, importantly, open up spaces in which students can be creative as well-while still meeting external demands regarding content and assessment.

Scrutinizing remix practices (and not just products) in classrooms, and engaging students in meaningful conversations about what it means to be "creative" within different practices opens up all sorts of potential for engaging them in creative appreciation and understanding that emphasizes how "being creative" is something that can be developed, refined and shared over time, rather than something one is simply born with. This kind of classroom work can also emphasize how "being creative" is not simply about being a member of a creative class or economy, but that creativity is a key element in all of us to living fully and well.

\section{Bibliography}

Beghetto, R., \& Kaufman, J. (Eds.) (2017). Nurturing creativity in the classroom (2nd ed.). New York: Cambridge University Press. https://doi.org/10.1017/9781316212899

Boccella, N., \& Salerno, I. (2016). Creative economy, cultural industries and local development. Procedia: Social and Behavioral Sciences, 223, 291-296. https://doi.org/10.1016/j.sbspro.2016.05.370

Burn, A. (2009). Making new media: Creative production and digital literacies. New York: Peter Lang. 
Burwell, C. (2013). The pedagogical potential of video remix: Critical conversations about culture, creativity and copyright. Journal of Adolescent \& Adult Literacy, 57(3), 205-213. https://doi.org/10.1002/JAAL.205

Cloonan, A., Hutchison, K., \& Paatsch, L. (2015). Creative, critical, digital: Connecting home and school literacies. Report prepared for Catholic Education Melbourne, Australia.

Craft, A. (2003). Limits to creativity in education: Dilemmas for the educator. British Journal of Educational Studies, 51(2), 113-127. https://doi.org/10.1111/1467-8527.t01-1-00229

Curwood, J. S., \& Gibbons, D. (2010). "Just like I have felt": Multimodal counternarratives in youth-produced digital media. International Journal of Learning and Media, 1(4), 59-77. https://doi.org/10.1162/ijlm_a_00034

Florida, R. (2012). The rise of the creative class: revisited. New York: Basic Books.

Gee, J. P. (2007). Good video games + good learning. New York etc.: Peter Lang.

Gee, J. P. (2012). Social linguistics and literacies: Ideologies in discourses (4th ed.). New York: Routledge.

Gee, J. P. (2013). Good video games + good learning (2nd ed.). New York etc.: Peter Lang.

Gee, J. P., Hull, G., \& Lankshear, C. (1996). The new work order: Behind the language of the new capitalism. Sydney: Allen \& Unwin.

Hinsdale, B. (1900). Teaching the language-arts: Speech, reading composition. New York: Appleton.

Jenkins, H., Ito, M., \& boyd, d. (2015). Participatory culture in a networked era. Cambridge: Polity.

Kaufman, J. C., \& Beghetto, R. A. (2009). Beyond big and little: The four C model of creativity. Review of General Psychology, 13(1), 1-12. https://doi.org/10.1037/a0013688

Knobel, M., \& Kalman, J. (Eds.) (2016). New literacies and teacher learning. New York: Peter Lang.

Knobel, M., \& Lankshear, C. (2014). Studying new literacies. Journal of Adolescent \& Adult Literacy, 58(2), 97-101. https://doi.org/10.1002/jaal.314

Lankshear, C., \& Knobel, M. (2011). New literacies: Everyday practices and social learning. Maidenhead: Open University Press.

Lankshear, C., \& Knobel, M. (2015). Creativity and language in digital remix. Keynote paper presented to Futuuri! Language Summer School and the Language Centre Conference, Jyväskylä, Finland, June 5.

Lessig, L. (2009). Remix. New York: Penguin.

Navas, E., Gallagher, O., \& burrough, x. (Eds.) (2015). The Routledge companion to remix studies. New York: Routledge.

Peppler, K. (2014). New creativity paradigms: Arts learning in the digital age. New York etc.: Peter Lang.

Runco, M., \& Albert, R. (2010). Creativity research: A historical approach. In J. Kaufman \& R. Sternberg (Eds.), The Cambridge handbook of creativity (pp. 3-19). Cambridge: Cambridge University Press.

Saldaña, J. (2016). The coding manual for qualitative researchers (3rd ed.). Thousand Oaks: Sage. 
Stickley, T., Parr, H., Atkinson, S., Daykin, N., Clift, S., De Nora, T., ... Hogan, S. J. (2017). Arts, health \& wellbeing: Reflections on a national seminar series and building a UK research network. Arts and Health, 9(1), 14-25. https://doi.org/10.1080/17533015.2016.1166142

Street, B. V. (1984). Literacy in theory and in practice. Cambridge: Cambridge University Press.

Võgotski, L. (1978). Mind in society. Cambridge: Harvard University Press.

Wilson, N. (2010). Social creativity: Re-qualifying the creative economy. International Journal of Cultural Policy, 16(3), 367-381. https://doi.org/10.1080/10286630903111621 


\section{Appendix 1. Published out-of-school remix studies}

Black, R. W. (2005). Access and affiliation: The literacy and composition practices of English language learners in an online fanfiction community. Journal of Adolescent \& Adult Literacy, 49(2), 118-128. https://doi.org/10.1598/JAAL.49.2.4

Black, R. W. (2006). Language, culture, and identity in online fanfiction. E-learning, 3(2), 170-184. https://doi.org/10.2304/elea.2006.3.2.170

Black, R. W. (2007). Digital design: English language learners and reader reviews in online fiction. In M. Knobel \& C. Lankshear (Eds.), A new literacies sampler (pp. 115-116). New York: Peter Lang.

Black, R. W. (2008). Adolescents and online fan fiction. New York: Peter Lang.

Black, R. W. (2009a). Adolescents, fan communities, and twenty-first century skills. Journal of Adolescent \& Adult Literacy, 52(8), 688-697. https://doi.org/10.1598/JAAL.52.8.4

Black, R. W. (2009b). Online fan fiction, global identities, and imagination. Research in the Teaching of English, 43(4), 397-425.

Black, R. W. (2009/2010). Online fan fiction and critical media literacy. Computing in Teacher Education, 26(2), 75-80.

Chandler-Olcott, K., \& Mahar, D. (2003). Adolescents' anime-inspired "fanfictions:" An exploration of multiliteracies. Journal of Adolescent \& Adult Literacy, 46(7), $556-566$.

Curwood, J. S. (2013a). Fan fiction, remix culture, and the Potter Games. In V. E. Frankel (Ed.), Teaching with Harry Potter (pp. 81-92). Jefferson: McFarland.

Curwood, J. S. (2013b). The Hunger Games: Literature, literacy, and online affinity spaces. Language Arts, 90(6), 417-427.

Curwood, J. S., Magnifico, A. M., \& Lammers, J. C. (2013). Writing in the wild: Writers' motivation in fan-based affinity spaces. Journal of Adolescent \& Adult Literacy, 56(8), 677-685. https://doi.org/10.1002/JAAL.192

Diakopoulos, N., Luther, K., Medynskiy, Y., \& Essa, I. (2007). Remixing authorship: Reconfiguring the author in online video remix culture. Technical Report (GIT-IC-07-05). Georgia Institute of Technology. Retrieved from https://smartech.gatech.edu/bitstream/handle/1853/19891/GIT-IC-07-05.pdf? sequence $=1$ \&isAllowed=y.

Domingo, M. (2014a). Migrating literacies: Multimodal texts and digitally enabled text making. Text \& Talk, 34(3), 261-282. https://doi.org/10.1515/text-2014-0002

Domingo, M. (2014b). Transnational language flows in digital platforms: A study of urban youth and their multimodal text making. Pedagogies, 9(1), 7-25. https://doi.org/10.1080/1554480X.2013.877554

Durga, S. (2012). Learning to mod in an affinity-based modding community. In E. R. Hayes \& S. C. Duncan (Eds.), Learning in video game affinity spaces (pp. 84-102). New York: Peter Lang.

Eleá, I. (2012). Fanfiction and webnovelas: The digital reading and writing of Brazilian adolescent girls. In K. Ross (Ed.), The handbook of gender, sex, and media (pp. 71-87). New York: Wiley-Blackwell. https://doi.org/10.1002/9781118114254.ch5

Frølunde, L. (2012). Animated war: Perspectives on resemiosis and authorship applied to two DIY film projects. Convergence, 18(1), 93-103.

https://doi.org/10.1177/1354856511419918 
Gustavson, L. (2008). Influencing pedagogy through the creative practices of youth. In M. L. Hill \& L. Vasudevan (Eds.), Media, learning, and sites of possibility (pp. 81-114). New York etc.: Peter Lang.

Hayes, E., \& Lee, Y. N. (2012). Specialist language acquisition and 3D modding in a Sims fan site. In E. R. Hayes \& S. C. Duncan (Eds.), Learning in video game affinity spaces (pp. 186-211). New York: Peter Lang.

Ito, M. (2010). The rewards of non-commercial production: Distinctions and status in anime music video scene. First Monday, 15(5). Retrieved from http://firstmonday.org/ojs/index.php/fm/article/view/2968/2528. https://doi.org/10.5210/fm.v15i5.2968

Ito, M., Baumer, J., Bittanti, M., boyd, d., Cody, R., Herr-Stephenson, B., ... Tripp, L. (2010). Hanging out, messing around, and geeking out: Kids living and learning with new media. Cambridge: MIT Press.

Jocson, K. M. (2013). Remix revisited: Critical solidarity in youth media arts. E-learning and Digital Media, 10(1), 68-82. https://doi.org/10.2304/elea.2013.10.1.68

Keegan, K. M. (2010). Visual literacy in online community interactions: PhotoShop contests at Fark.com. International Journal of Technology, Knowledge and Society, 6(4), 165-178. https://doi.org/10.18848/1832-3669/CGP/v06i04/56118

Knobel, M., \& Lankshear, C. (2007). Online memes, affinities and cultural production. In M. Knobel \& C. Lankshear (Eds.), A new literacies sampler (pp. 199-228). New York: Peter Lang.

Lammers, J. C., \& Marsh, V. L. (2015). Going public: An adolescent's networked writing in Fanfiction.net. Journal of Adolescent \& Adult Literacy, 59(3), 277-285. https://doi.org/10.1002/jaal.416

Magnifico, A. M. (2012). The game of neopian writing. In E. R. Hayes \& S. C. Duncan (Eds.), Learning in video game affinity spaces (pp. 212-234). New York: Peter Lang.

Magnifico, A. M., Curwood, J. S., \& Lammers, J. C. (2015). Words on the screen: Broadening analyses of interactions among fanfiction writers and reviewers. Literacy, 49(3), 158-166. https://doi.org/10.1111/lit.12061

Skågeby, J. (2011). Dismantling the guitar hero? A case of produced parody and disarmed subversion. Convergence, 19(1), 63-76. https://doi.org/10.1177/1354856512456791

Stedman, K. (2012). Remix literacy and fan compositions. Computers and Composition, 29(2), 107-123. https://doi.org/10.1016/j.compcom.2012.02.002

Strong, K., \& Ossei-Owusu, S. (2014). Naija boy remix: Afroexploitation and the new media creative economies of cosmopolitan African youth. Journal of African Cultural Studies, 26(2), 189-205. https://doi.org/10.1080/13696815.2013.861343

Steinkuehler, C., \& Johnson, B. Z. (2009). Computational literacy in online games: The social life of mods. International Journal of Gaming and Computer-Mediated Simulations, 1(1), 53-65. https://doi.org/10.4018/jgcms.2009010104

Thomas, A. (2006). Fan fiction online: Engagement, critical response and affective play through writing. Australian Journal of Language and Literacy, 29(3), 226239.

Thomas, A. (2007a). Youth online: Identity and literacy in the digital age. New York: Peter Lang. 
Thomas, A. (2007b). Blurring and breaking through the boundaries of narrative, literacy, and identity in adolescent fan fiction. In M. Knobel \& C. Lankshear (Eds.), A new literacies sampler (pp. 137-166). New York: Peter Lang.

Trainor, J. (2004). Critical cyberliteracy: Reading and writing: The X-files. In J. Mahiri (Ed.), What they don't learn in school: Literacy in the lives of urban youth (p. 123138). New York: Peter Lang.

Turk, T., \& Johnson, J. (2012). Toward an ecology of vidding. Transformative Works and Cultures, 9(1). Retrieved from http://journal.transformativeworks.org/index. php/twc/article/view/326/294. 